\title{
A FILOSOFIA SEMÂNTICA TRADICIONAL: UMA ABORDAGEM ENTRE FREGE E RUSSELL
}

Bruno Fernandes de Oliveira ${ }^{1}$

\section{Resumo}

O objetivo deste artigo é apresentar o que Friedrich Ludwig Gottlob Frege (1848-1925) entende sobre sentido (Sinn) e referência (Bedeutung) dos nomes próprios e das sentenças assertivas completas e a crítica que Bertrand Russell (1872 - 1970) faz ao sentido fregeano, ou seja, uma sentença não tem sentido como Frege propõe, ela simplesmente denota. A investigação far-se-á através da obra Sobre o Sentido e a Referência - Über Sinn und Bedeutung - [2009 (1892)], na qual Frege propõe uma distinção entre os termos e da obra Da Denotação - On Denoting - [1978 (1905)], na qual Russell sustenta que uma expressão só denota. Não é a minha intenção fazer uma abordagem minuciosa, e sim apresentar a distinção entre sentido e referência para Frege, e analisar como Russell tenta resolver o paradoxo semântico fregeano. É neste sentido que este artigo se norteará.

Palavras Chave: Frege; Russell; Semântica; Sentido; Referência.

\section{Abstract}

This article's purpose is to introduce the understanding of Friedrich Ludwig Gottlob Frege (18481925) with regards to sense (Sinn) and reference (Bedeutung) of names and complete assertive sentences, and the criticism that Bertrand Russell (1872 - 1970) makes to the fregean sense, which in summary says that a sentence does not have sense as Frege proposes, it just denotes it. The research shall be carried out through the work On the Sense and Reference - Über Sinn und Bedeutung - [2009 (1892)], where Frege proposes a distinction between the terms and of the work On Denoting - [1978 (1905)], where Russell sustains that an expression only denotes. It is not my intention to do a thorough approach, but to present the distinction betweeen sense and reference to Frege, and analyze how Russel tried to solve the fregean semantic paradox. It is in this direction that this article will be developed.

Keywords: Frege; Russell; Semantic; Sense; Reference.

\footnotetext{
${ }^{1}$ Mestrando do Programa de Pós-graduação em Filosofia da Universidade Estadual do Oeste do Paraná (UNIOESTE), professor no Instituto Sapientia de Filosofia em Francisco Beltrão - PR.
} 


\section{Introdução}

A linguagem, nos últimos anos, é sem dúvida uma das áreas que mais desenvolveu na historia da filosofia. Sem dúvida, hoje, é o ramo da filosofia que mais produz trabalhos, no âmbito filosófico. No entanto, não foi sempre assim. A filosofia da linguagem conheceu o seu apogeu somente no início do século XX, período de grande influência para o novo modo de pensar filosófico e com grandes contribuições para à filosofia. Filósofos como Gottlob Frege, Bertrand Russell, Rudolf Carnap, Wittgenstein, Quine entre outros, apresentaram uma nova mentalidade, em filosofia. Nesse sentido, pode se afirmar que a filosofia da linguagem começa a dar seus primeiros passos com o filósofo Gottlob Frege. Dentre seus escritos, Frege deu grande importância à teoria do significado, ou seja, retomou novamente o problema do significado das sentenças, que de certa forma havia sido abandonado pela história da filosofia. Posteriormente, Russell deu sua contribuição a esta teoria. Tais contribuições podem ser caracterizadas como "Teoria Semântica Tradicional".

O termo "teoria semântica tradicional" foi atribuído para representar as primeiras teorias semânticas contemporâneas, como as de Frege, Russell, primeiro Wittgenstein, Carnap, entre outros, no qual sustentavam que a referência é determinada por estados mentais, ou seja, saber o significado de um termo é apenas uma questão de estar em um determinado estado mental e a intenção (sentido) de um termo determina a sua extensão (referência). Portanto, se é apenas uma questão de estar em um determinado estado mental e a intenção determina a extensão, pode-se afirmar que é o estado psicológico que determina o significado.

O objetivo deste artigo é apresentar o que o filósofo e matemático alemão Gottlob Frege entende sobre sentido (Sinn) e referência (Bedeutung) dos nomes próprios e das sentenças assertivas completas e a critica que o filósofo Bertrand Russell faz a filosofia semântica fregeana, que uma sentença só denota. Pretendemos mostrar como Russell tenta resolver o paradoxo semântico fregeano, que um nome próprio e uma sentença podem possuir valores cognitivos diferentes para a mesma referência. No que se segue apresentaremos de forma mais detalhada.

\section{FREGE: TEORIA DO SIGNIFICADO}

Antes de qualquer desenvolvimento é de extrema importância apresentar o que Frege diz sobre: nome próprio, sinal, referência e sentido. Por nome próprio Frege entende uma expressão que se refere a um objeto determinado ou algumas descrições definidas - que são combinações de palavras ou sinais -, são alguns exemplos de nomes próprios, na concepção fregeana: 'Ulisses', 'Aristóteles', ‘A capital de São Paulo', 'Venus', 'O autor da obra Ética a Nicômaco' entre outros. Segundo Frege “(...) fica claro que, por 'sinal' e por 'nome', entendo qualquer designação que desempenhe o papel de um nome próprio, cuja referência seja um objeto determinado (...), mas não 
um conceito ou uma relação" (FREGE, 2009, p.131). Todo nome próprio tem um sentido e tem que se referir a um objeto.

Frege entende por 'sinal' qualquer coisa que se remete a nome, combinação de palavras ou letras. Por 'referência', entende tudo que se remete a um objeto, ou seja, a referência é o próprio objeto designado pela expressão semântica. E por 'sentido', como o modo de manifestação do objeto, qual ele se apresenta.

Após apresentarmos o que Frege pensa por nome próprio, sinal, referência e sentido, precisamos entender o que ele elabora para distinguir sentido de referência. No início do seu artigo "Sobre o Sentido e a Referência" ele apresenta uma relação da igualdade, " $a$ é o mesmo que $b$ " ou “ $a$ e $b$ coincidem" (Cf. FREGE, 2009, p. 129). A proposta fregeana é que a referência de $a$ e $b$ são as mesmas, mas os sentidos são diferentes. Mas como entender essa tese inicial? Ele apresenta um exemplo de um triângulo. Sejam $A^{\prime}, B^{\prime}, C^{\prime}$, as linhas que unem os vértices de um triângulo com o ponto médio de seus respectivos lados opostos. O ponto de interseção de $A$ ' e $B$ ' é $G$, e o ponto de interseção de $B$ ' e $C$ ' é $G$, portanto, o ponto de interseção de $A$ ' e $B$ ' é o mesmo que $B$ ' e $C$ '. Sendo assim, temos diferentes designações para o mesmo ponto. Segue a ilustração do triângulo, na qual Frege propõe.

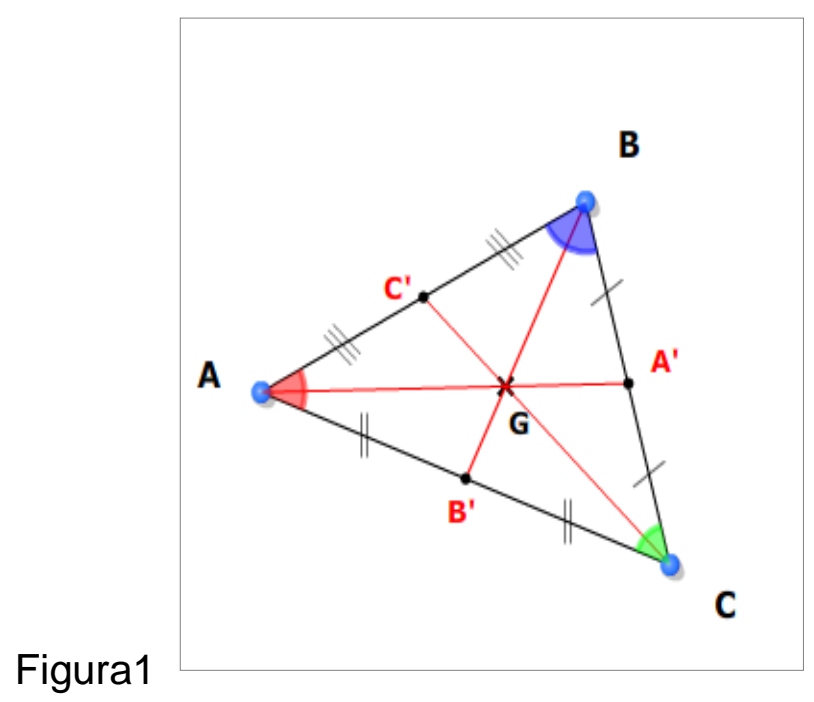

Esse exemplo ilustra como a referência pode ser a mesma, mas o sentido não. Fica claro com o exemplo da "estrela da manhã" e "estrela da tarde" (podemos observar que aqui a referência também é a mesma, mas o sentido muda).

Para melhor esboçar essa problemática que Frege levanta em torno dos nomes próprios, partiremos da seguinte pergunta: a igualdade da referência pressupõe a igualdade do sentido? Se utilizarmos o exemplo da "estrela da manhã" e "estrela da tarde", nos quais ambos referem ao planeta Vênus, afirmaríamos que os nomes podem se referir ao mesmo objeto, já que no inicio do Unioeste campus Toledo - Paraná 
texto apresentamos uma formulação em que todos os nomes próprios têm que ter um sentido e referir a um objeto e, que essa referência seja acerca de um objeto determinado. Nessa situação responderíamos a pergunta acima com um simples, não. Ou seja, a igualdade da referência não pressupõe a igualdade do sentido, isto é, "estrela da manhã" e "estrela da tarde" tem sentidos diferentes e referem ao mesmo objeto. Frege diz que o sentido de um nome próprio não garante a referência, ou seja, podem existir nomes próprios com sentido e sem referência, dado que o sentido sempre se refere a um objeto. ${ }^{1} \mathrm{O}$ exemplo que Frege apresenta para esboçar sua teoria é a partir das seguintes expressões "o corpo celeste mais distante da terra" e "a série que converge menos rapidamente" (FREGE, 2009, p. 133). As expressões têm sentidos, mas não conseguimos determinar as suas referências; utilizando o próprio termo que Frege emprega em seu artigo, "é muito duvidoso que também tenha uma referência" (FREGE, 2009, p. 133). Logo, apreender um sentido não assegura a existência de sua referência.

Após apresentar evidências objetivas de que apreender um sentido não assegura a existência de sua referência, Frege investiga outro problema acerca da 'representação' (Vorstellung) ${ }^{2}$. Tratase de saber se a ideia ou representação é objetiva ou subjetiva, e, assim, se o sentido pode ser compreendido por diversas pessoas. Frege analisa a questão e logo afirma, com muita clareza, que não se deve confundir a ideia com o sentido e com a referência. Sendo assim, a ideia é uma imagem interna repleta de emoções. Frege alerta que existem diferenças entre os indivíduos que se manifestam, isto é, quando cada um desses indivíduos apreendem uma representação. Assim, não se deve confundir a representação com o sentido e com a referência. Segundo Frege, "um pintor, um cavaleiro e um zoólogo provavelmente associarão ideias muito diferentes ao nome Bucéfalo" (FREGE, 2009, p. 134), portanto, a representação é de natureza subjetiva e cada homem possui a sua, sendo, entretanto, incomunicável.

Em relação ao sentido, não é verdade que ele é subjetivo, mas também não é o próprio objeto, de modo que, pessoas distintas podem apreender o mesmo sentido, mas a ideia que elas terão ainda será interno-subjetiva. "Importa salientar a distinção entre a representação que é permeada de emoções e o sentido e a referência que, Frege pretende, são isentos dessa influência" (SCHORN, 2009, p. 44). Para melhor exemplificar esse problema, Frege apresenta a metáfora do telescópio. Esse exemplo consiste na seguinte estrutura: com um telescópio observamos a lua, nessa observação, a lua consiste na referência, ou seja, é o próprio objeto. A imagem que temos na lente interna ao telescópio consiste no sentido e a imagem na retina do observador consiste na representação, ideia - nesse exemplo, Frege está apresentando de forma didática a diferença entre referência, sentido e a representação, - a imagem da lua refletida na lente no interior do telescópio é 
objetiva; é a imagem que se apresenta a todos os observadores, mas a imagem refletida na retina do olho do observador é subjetiva, assim, cada observador terá a sua própria imagem, dado que, cada indivíduo tem sua própria configuração nos olhos. Dessa forma, percebe-se a diferença entre referência, sentido e representação. Portanto, a representação é subjetiva e cada indivíduo possui a sua, sendo o oposto com o sentido que é objetivo e com a referência.

Passamos agora a investigar as sentenças assertivas completas. Frege admite que as sentenças também tenham sentido e referência, ou seja, uma dupla função semântica e que todas as sentenças constituem um pensamento (Gedanke), isto é, um conteúdo proposicional. Cabe, metodologicamente, questionar: o que Frege entende por pensamento ${ }^{3}$

Pensamento para Frege não é subjetivo, ou seja, não é acerca de um conteúdo psicológico ou um processo psicológico, mas, sim, um conteúdo objetivo que pode ser compartilhado em comum por muitos indivíduos.

O pensamento deve ser considerado referência ou sentido? Para Frege o pensamento é o sentido e para isso ele apresenta um exemplo, no qual sustenta que a referência não pode ser considerada como pensamento. Nesse caso, se substituirmos uma referência de uma sentença por outra referência de igual valor e que os sentidos são diferentes, a substituição não poderá ter nenhuma influência sobre a referência. Nesse sentido, apresentamos o exemplo que Frege utiliza para provar que o pensamento muda quando trocamos a referência por outra; por exemplo, o pensamento da sentença: "A estrela da manhã é um corpo iluminado pelo sol” é diferente da sentença "A estrela da tarde é um corpo iluminado pelo sol”. Se alguém não soubesse que "A estrela da manhã" é a mesma que "A estrela da tarde" poderia afirmar que um pensamento é verdadeiro e o outro falso (FREGE, 2009, p. 137). Portanto, o pensamento é objetivo, não pode ser associado à referência da sentença, mas, sim, com o seu sentido.

Frege apresenta que uma função proposicional ${ }^{4}$ ao ser completada por um elemento qualquer poderá ser transformada em um pensamento, sendo assim podendo atribuir um sentido. $\mathrm{O}$ que queremos dizer é que, por exemplo, em uma expressão insaturada como:

"x é a capital do Paraná"

Se substituirmos a variável ' $\mathrm{x}$ ' por Curitiba, temos a seguinte expressão:

"Curitiba é a capital do Paraná"

A expressão saturada apresenta um sentido. Entendemos que, para Frege se a expressão permanecesse com a variável não estaria completa e com isso não poderíamos atribuir sentido a ela. Mas quando substituímos a variável por Curitiba, a expressão apresenta um sentido, ou seja, um pensamento. 
A distinção que Frege faz de sentido e referência de uma sentença assertiva completa é que o pensamento corresponde ao sentido e a referência é aquilo que permanece quando o sentido de uma sentença muda. A referência se relaciona com o objeto e, quando pensamento muda, a referência deve permanecer a mesma. Frege afirma que a referência de uma sentença assertiva completa deve ser denominada como $o$ valor de verdade. O valor de verdade de uma sentença deve ser verdadeiro ou falso; ou como Frege chama, de o verdadeiro e o outro de o falso (Cf. FREGE, 2009, p. 139).

Frege alerta que, somente o pensamento não confere nenhum conhecimento, mas quando é associado à sua referência, ao seu valor de verdade, acabamos produzindo conhecimento (FREGE, 2009, p. 140). O pensamento e a referência dependem um do outro para produzir conhecimento. Segundo Schorn:

\begin{abstract}
Importa ultrapassar o pensamento e alcançar a possibilidade da referência como forma de estabelecer o valor de verdade das expressões, instância exclusiva dos juízos. A verdade implica buscar a referência do sentido; assim, somente necessitamos da referência quando investigamos a verdade das sentenças assertivas. Então, a referência coincide com o valor de verdade e a sentença é considerada um nome próprio. É da referência de um nome que um predicado é afirmado ou negado e, sem admitir-se a existência de uma referência, não se pode atribuir ou negar um predicado; pode, no entanto, haver pensamento. Assim, Frege passa do plano do pensamento para o plano da referência relativamente aos juízos. Os juízos são apreensões verdadeiras do sentido e da referência. $O$ pensamento que não passa do sentido, não alcança o valor de verdade; permanece na relação lógica entre sujeito e predicado. Com sujeito e predicado pode-se chegar a um pensamento; entretanto é impossível passar do sentido à referência, característica dos juízos, pois carece-lhe o alcance ao valor de verdade. Ao afirmar- se que determinado sujeito tem um predicado, não se diz nada do sujeito nem do predicado que implique a existência tanto de um quanto de outro (SCHORN, 2009, p. 46).
\end{abstract}

Qual era o objetivo de Frege ao separar sentido e referência para os nomes próprios e para as sentenças assertivas $?^{5}$

Frege ao separar as sentenças assertivas completas, argumenta que os nomes próprios funcionam como sujeitos das sentenças e esses nomes tem como função determinar o valor de verdade das sentenças, caso inverso acontece com o pensamento que carece de referência. Os nomes não precisam referir, sendo a eles somente cabível de sentido. Portanto, se é um pensamento sem referência, então não é portador de um valor de verdade.

Após apresentar o que Frege entende por nomes próprios e por sentenças assertivas. Tentaremos compreender qual era o objetivo de Frege ao tratar da questão da igualdade, isto é, a diferença entre $a=a$ e $a=b$.

Sabemos que no início de seu artigo, Frege destaca que $a=a$ e $a=b$ tem valores cognitivos diferentes e que $a=a$ é $a$ priori, portanto, não é ampliador de conhecimento. Contudo, isso não 
acontece $\operatorname{com} a=b$, que na realidade agrega conhecimento. A hipótese que Frege apresenta no final do seu artigo é que, se ' $a$ ' e ' $b$ ' tiverem a mesma referência, não impede os sentidos de serem distintos ou diferentes. Para ter um valor cognitivo relevante a referência deve ser acerca do mesmo objeto, mas com sentidos distintos. Quando expressamos um pensamento acerca de 'o autor de Teeteto' e 'o mestre de Aristóteles', o sentido se manifesta de forma diferente, ou seja, temos um valor cognitivo distinto, mas a referência é a mesma. Tanto 'o autor de Teeteto', quanto 'o mestre de Aristóteles' denota de Platão. Portanto, o sentido de ' $b$ ' difere do sentido ' $a$ ', isto é, o pensamento que temos acerca de " $a=b$ " pode diferir do pensamento que temos acerca de " $a=a$ ", temos assim um valor cognitivo diferente e a igualdade não é trivial.

Com a publicação do artigo "Sobre o Sentido e a Referência", Frege faz uma grande contribuição à filosofia da linguagem, à lógica e à linguística, no qual ele retoma questões que não tinham mais interesse para a própria lógica e a filosofia, como no caso de uma semântica possível. Com isso, acaba desencadeando discussões que permanecem em aberto até o presente momento. Vale destacar que Russell foi um grande crítico de Frege. Em seu artigo On Denoting [1978 (1905)] ele apresenta uma solução ao paradoxo fregeano, - que a mesma referência pode ter valores cognitivos ou sentidos diferentes -, e através da sua teoria das descrições afirma que nomes próprios somente denotam e não possuem sentido como Frege mostra. No que se segue, trataremos a teoria das descrições de Russell.

\section{RUSSELL: TEORIA DAS DESCRIÇÕES}

Para uma melhor compreensão do texto se faz necessário apresentar a noção fundamental da teoria das descrições russelianas. Essas noções são acerca da "função proposicional" e de "quantificadores". Russell já no seu artigo destaca a importância da função proposicional como principio da teoria da denotação.

Em seu livro "Introdução à Filosofia da Matemática" (1981), Russell definiu que proposição é a forma de uma sentença, que expressa ou o verdadeiro ou o falso. Já a função proposicional é a expressão que contém uma ou mais variáveis e quando atribuímos valores a tais variáveis a expressão se torna uma proposição. Desse modo, a expressão "x é humano" é uma função proposicional, na qual, ' $\mathrm{x}$ ' é indeterminado e não atribuímos qualquer valor como o verdadeiro ou $\mathrm{o}$ falso. Mas quando substituímos a variável 'x' por uma palavra, ou seja, "João é humano” podemos atribuir a essa expressão que ela pode ser verdadeira ou falsa (Cf. RUSSELL, 1981 p. 150). Sendo assim, a função proposicional não é nem verdadeira e nem falsa, ao passo que quando substituímos seus constituintes indeterminados por palavras ela torna-se proposição. 
Já para quantificadores Russell afirma que "são as mais primitivas das expressões denotativas" (RUSSELL, 1978, p.04), no caso as palavras tudo, nada e algo são quantificadores. Para melhor compreensão trataremos da seguinte forma:

$\mathrm{C}$ (tudo) significa " $\mathrm{C}(\mathrm{x})$ é sempre verdadeira";

$\mathrm{C}($ nada) significa " $\mathrm{C}(\mathrm{x})$ é sempre falsa";

$\mathrm{C}($ algo) significa " $\mathrm{C}(\mathrm{x})$ é algumas vezes verdadeira”.

As expressões ficariam da seguinte forma se substituirmos o ' $\mathrm{x}$ ':

Todo homem é humano significa que "o homem x é humano" é sempre verdadeira;

Nenhum homem é humano significa que "o homem x é humano" é sempre falsa;

Algum homem é humano significa que "o homem x é humano" é algumas vezes verdadeira.

Agora trataremos sobre as expressões definidas, as quais contém o artigo $o(a)$. Tomemos como exemplo a descrição o pai de Carlos II. A proposição quer dizer que existe um único indivíduo que é o pai de Carlos II. É nesse sentido que Russell diz que o artigo o envolve unicidade. Ou seja, quando expressamos o artigo definido estamos tratando somente de um indivíduo, caso inverso acontece com o artigo indefinido. Tomemos como exemplo: quando falamos que "o filho de fulano faleceu" e esse tal fulano tem mais de um filho, o correto seria afirma que "um filho de fulano faleceu". Caso acontece com o exemplo de o pai de Carlos II, que o artigo $o$ está envolvendo unicidade. É por esse motivo que afirmamos que x era o pai de Carlos II, sendo que 'x' tem certa relação com Carlos II (Cf. RUSSELL, 1978, p. 05).

O que Russell está querendo tratar em sua teoria é mostrar que sua proposta não vai cair no mesmo erro de Frege e de Meinong como o caso das descrições vazias. Por conta disso, ele apresenta uma solução que se segue: "x gerou Carlos II" e para obter um equivalente de "x era o pai de Carlos II" deve-se acrescentar "se y gerou Carlos II, y é idêntico a x". Portanto, "x é o pai de Carlos II”, torna-se: “x gerou Carlos II; e 'se y gerou Carlos II, y é idêntico a x' é sempre verdadeira para y" (RUSSELL, 1978, p.05).

Para Russell, a teoria de Meinong sobre os objetos não subsistirem e a teoria do Frege sobre algumas sentenças não denotarem, como no caso "o rei do Brasil”, denotam a classe vazia, o mesmo para expressões denotativas que possuem significados e denotação devem ser evitadas. E, para provar que sua teoria é capaz de resolver o problema da denotação, Russell apresenta três enigmas: 
(I) Se $a$ é idêntico a $b$, o que quer que seja verdadeiro em um é verdadeiro no outro, e até mesmo pode-se substituir um pelo outro em qualquer proposição sem alteração da verdade ou falsidade dessa proposição (RUSSELL, 1978, p. 08).

O primeiro enigma expressa a igualdade entre $a$ e $b$, ou seja, é um problema acerca da substituibilidade. Nesse caso, se apresentarmos as seguintes sentenças:

1- "Dilma é a presidente do Brasil";

2- "a atual presidente do Brasil".

Via de regra, "Dilma" e "a atual presidente do Brasil" equivalem semanticamente, contribuem para o significado da frase. O que estamos dizendo é que "Dilma" e "a atual presidente do Brasil" se referem ao mesmo objeto ou ela significam a mesma coisa.

Se considerarmos tal hipótese e substituirmos uma pela outra, não pode alterar o valor da proposição. De tal modo, se substituirmos “Dilma”, na sentença: "Dilma gosta de viajar" por "a atual presidente do Brasil", ficaria:

3- "a atual presidente do Brasil gosta de viajar"

Percebemos que a substituição não alterou o valor de verdade da proposição. Mas se utilizarmos um exemplo diferente.

Imagine uma nova sentença:

4- "João deseja saber se Dilma é a atual presidente do Brasil".

Vamos utilizar a mesma proposta feita acima e tal sentença resultaria em:

5- "João deseja saber se Dilma é Dilma"

Ou seja, utilizamos o mesmo princípio da identidade, mas percebemos que o valor de verdade foi alterado, já que, João não deseja saber se Dilma é Dilma e sim se Dilma é a atual presidente do Brasil. 
(II) Pela lei de exclusão dos meios, ou “A é B" ou "A não é B" deve ser verdadeira. Portanto, ou "o atual rei da França é careca" ou "o atual rei da França não é careca” deve ser verdadeira (RUSSELL, 1978, p.08).

O segundo enigma pode ser caracterizado como o enigma do terceiro excluído e para melhor exemplificar isso imagine-se duas sentenças:

1- "Dilma é careca";

2- "Dilma não é careca".

Sabemos que a sentença 1 é falsa e a sentença 2 é verdadeira, haja vista que, temos o conhecimento de que a Dilma não é careca. O que acontece em tal problema é que o termo singular "Dilma" não é careca, implica a falsidade da outra, ou seja, a sentença 1 é falsa e a sentença 2 é verdadeira. Sendo assim, não há nenhuma hipótese de haver uma terceira opção. Mas se pensarmos em outra hipótese como:

$$
\begin{aligned}
& \text { 3- "O atual rei do Brasil é calvo"; } \\
& \text { 4- "O atual rei do Brasil não é calvo". }
\end{aligned}
$$

Caso utilizarmos o exemplo anterior diríamos que a sentença 3 ou a 4 é verdadeira e que implica a falsidade da outra, sendo assim, não havendo possibilidade de uma terceira opção. Mas sabemos que o Brasil carece de um rei, contudo, ele não está entre as coisas carecas e não carecas, e isso contraria a teoria mencionada acima.

Esse enigma causa um dilema. Podemos dizer que as sentenças 3 e 4 carecem de significado, haja vista que o Brasil não possui um rei. Assumimos, por um lado, que tais sentenças não possuem significados. Por outro lado podemos afirmar que isso é absurdo, pois somos capazes de entender as sentenças e, por isso, elas são dotadas de significado. Devemos levar em conta que "o atual rei do Brasil” é uma descrição definida. Se as sentenças possuem significados, elas automaticamente devem possuir valor de verdade. Mas tal dilema poderia causar um grande problema e com isso teríamos que partir da seguinte indagação: como atribuímos o valor de verdade e o falso as coisas que não existem?

(III) Considere-se a proposição “A difere de B". Se isto é verdade, existe uma diferença entre A e B, fato que se pode expressar sob a forma "a diferença entre A e B subsiste". Mas se é 
falso que $\mathrm{A}$ difere de $\mathrm{B}$, então não existe diferença alguma entre $\mathrm{A}$ e $\mathrm{B}$; fato que se pode expressar sob a forma: "a diferença entre A e B não subsistem” (RUSSELL, 1978, p. 08).

O terceiro enigma é acerca das coisas negativas, ou seja, sobre a teoria do Meinong. Ele propõe que as confusões acontecem porque não notamos a distinção entre ser e não ser (sosein). $\mathrm{O}$ que ele está tratando é que por mais que as coisas não existem no mundo real, elas possuem propriedades, isto é, "o atual rei do Brasil" não existe, mas possui a propriedade de ser rei. O mesmo acontece com Papai Noel, Coelhinho da Páscoa entre outros. Em resumo, Meinong está basicamente dizendo que todos os objetos têm propriedade, eles existindo ou não. E o que falta para ele existir é a propriedade de existir. Se levarmos em conta tal teoria poderíamos afirmar que o Brasil possui um atual rei. Mas não pretendo detalhar a teoria de Meinong.

Russell ao desenvolver sua teoria das descrições divide as descrições como definidas e indefinidas. As descrições definidas são aquelas que selecionam um objeto definido e, o caso inverso acontece com a segunda, ou seja, as descrições indefinidas não têm um objeto definido particular. Um exemplo típico de descrições definidas é "a atual presidente do Brasil” e também “o filho de fulano de tal", esses exemplos demonstram que o artigo $o(a)$ seleciona um objeto definido e particular. Já para as descrições indefinidas apresentamos os seguintes exemplos: "um presidente do Brasil" e "um filho de fulano de tal", percebemos que o artigo indefinido um pode selecionar diversos objetos. Russell tem uma maior preocupação com as descrições definidas e por conta dessa preocupação ele divide-as em ocorrências primárias e secundárias.

A diferença das ocorrências é acerca de que quando uma descrição definida implica a existência de um objeto e isso satisfaz a descrição, é considerada primária; quando não o implica é secundária.

Segundo Russell, quando usamos os termos singulares "George IV" e "o autor Waverley", e dizemos "George IV desejava saber se Scott era o autor de Waverley", isso implica que queremos dizer que "George IV desejava saber se um e somente um homem é "o autor de Waverley", e George IV desejava saber se Scott era esse homem” (Cf. Russell, 1978, p. 11). Assim sendo, a última proposição é ocorrência primária e a primeira proposição uma ocorrência secundária.

A última proposição poderia ser expressa da seguinte maneira; "George IV desejava saber, com respeito ao homem que de fato escreveu Waverley, se ele era Scott". Notamos que na ocorrência primária George IV deseja saber se um e somente um homem escreveu Waverley e esse homem era Scott, com isso percebemos que a existência do objeto satisfaz a descrição.

Vejamos a construção que Russell apresenta sobre o segundo enigma. Sabemos que o enigma trata das formas que podemos dar às proposições verdadeiras acerca das coisas que não 
existem. Contudo, se pensarmos: "o atual rei da França é careca ou não é careca"; podemos dizer que essa frase não denota nada, já que Russell apresenta no inicio do artigo Da Denotação que uma expressão pode ser denotativa e não denotar nada (Cf. Russell, 1978, p. 01). Mas para resolver o enigma ele apresenta que quando esta descrição é uma ocorrência primária, a proposição é falsa e quando a ocorrência é secundária a proposição pode ser verdadeira. Para entender esse problema apresentemos os seguintes exemplos.

Na ocorrência primária a sentença que segue é a seguinte:

"Existe uma entidade que é agora rei da França e é careca"

A descrição "rei da França" é primária e implica um único rei da França. Mas sabemos que a França carece de um rei e com isso podemos afirmar que a sentença é falsa. Para as descrições definidas que empregam uma negação temos que destacar dois casos: uma é verdadeira e a outra é falsa. Nesse sentido, temos:

“o atual rei da França não é careca”,

Essa proposição ficaria:

“Existe uma entidade que é agora rei da França e não é careca".

De fato essa proposição é falsa, mas é verdadeira se significada:

“é falso que existe uma entidade que é agora rei da França e não é careca” (Cf. Russell, 1978, p. 12).

Essa descrição é secundária, mas a proposição é verdadeira. O que percebemos é que na primeira, a negação aparece depois do quantificador e, na segunda, a negação é anterior, dando assim, uma maior importância à negação e não ao quantificador. Como vemos, as ocorrências primárias e secundárias dão conta dos enigmas apresentado acima. "Para Russell, a situação da expressão 'o atual rei da França' é a mesma de termos como 'Pégaso' e 'Papai Noel'" (DUTRA, 2014, p. 113). 


\section{Considerações}

Percebemos que a teoria das descrições desenvolvida por Russell mostra que a teoria de Frege falha ao afirma que um nome próprio apresenta sentido e não denota nada. Com isso, ele esclarece a teoria da igualdade de Frege, $a=b$, é absurda e que deve ser evitada. Como vimos no texto, Russell mostra que $a=b$ não é possível. Portanto, ele acredita que a teoria das descrições é capaz de resolver o paradoxo criado por Frege. Podemos, porém, observar que seu atomismo lógico também falha em determinadas ocasiões. Para Russell os nomes têm significados quando temos familiaridade com o objeto. Contudo, essa ideia traz consigo uma grande dificuldade. Nesse sentido, quando referíamos a um objeto que existe, podemos atribuir um significado a ele por familiaridade. Caso inverso acontece quando o objeto não existe, dessa forma, não podemos atribuir significado ao objeto. Devemos levar em consideração que na linguagem ordinária atribuímos significados a determinados nomes que não existem, como por exemplo: Homero. Russell se defende afirmando que nomes como Homero são conhecidos meramente por descrições, sendo assim, Homero é conhecido por uma descrição como: "o autor de Ilíada e da Odisséia". Portanto, Russell afirma que esses nomes não são nomes, podemos, somente, afirmar que esses nomes são verdadeiros partindo de uma descrição. O conhecimento se dá através de descrição e não por familiaridade. A teoria das descrições de Russell posteriormente atravessou por um momento de críticas, P.F. Strawson, Saul Kripke e Donnellan apresentaram suas teses contra Russell, porém não é do meu interesse discutir tais críticas e sim apresentar como o significado se dá na doutrina tradicional semanticista.

\section{Notas}

\footnotetext{
${ }^{1}$ Frege admite que realmente podem existir nomes próprios que expressam sentido, mas não uma referência, isso pode ser denominado de conjunto vazio e tais nomes devem ser evitados em frases científicas, pois, eles não expressam nada acerca da verdade e nem do falso.

${ }^{2} \mathrm{O}$ termo Vorstellung pode ser traduzido do alemão para o português como ideia ou representação.

${ }^{3}$ Frege reserva um ensaio intitulado Der Gedanke (O Pensamento) (1918), na qual ele dedica um trabalho mais profundo acerca do pensamento.

${ }^{4}$ Função proposicional é uma expressão designada por $\mathrm{F}(\mathrm{x})$, na qual essa variável pode ser substituída por um elemento A, sendo assim F (A) Verdadeira ou F (A) Falsa.

${ }^{5} \mathrm{Na}$ Begriffsschrift (Conceitografia) - 1879 Frege destaca que seu objetivo é de construir uma linguagem logicamente perfeita e essa linguagem se dá somente com a linguagem artificial, ou seja, formal.
} 


\section{Referências bibliográficas}

DUTRA, L. H. de A. Filosofia da Linguagem: introdução crítica à semântica filosófica. Florianópolis: Ed. da UFSC, 2014.

FREGE G. "Sobre o Sentido e a Referência. In: Lógica e Filosofia da Linguagem. 2.ed.cunhar São Paulo: Ed. Edusp, 2009.

PRADO, L. L. Alguns aspectos da teoria da proposição em Frege. Integração (USJT), São Paulo, v. 30, p. 173-176, 2002.

RUSSELL, B. "Da Denotação". In: Ensaios Escolhidos. São Paulo: Abril Cultural, 1978. (Os Pensadores).

1981.

. Introdução à Filosofia Matemática. Trad. Giasone Rebuá. Rio de Janeiro: Zahar Editores,

SCHORN, R. Sentido e Referência na Semântica de Frege. Humanidades em Revista/Filosofia, v. 08, p.39-51, 2009. 